African Crop Science Journal by African Crop Science Society is licensed under a Creative Commons Attribution 3.0 Uganda License. Based on a work at www.ajol.info/ and www.bioline.org.br/cs DOI: https://dx.doi.org/10.4314/acsj.v28i4.1

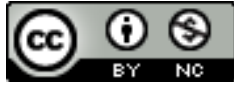

\title{
PERFORMANCE OF DUAL-PURPOSE PEARL MILLET GENOTYPES IN WEST AFRICA: IMPORTANCE OF MORPHOLOGY AND PHENOLOGY
}

\author{
D.D. SERBA, O. SY ${ }^{1}$, M.D. SANOGO ${ }^{2}$, A. ISSAKA ${ }^{3}$, M. OUEDRAOGO ${ }^{4}$, I.K. ANGO ${ }^{5}$, \\ I. DRABO ${ }^{4}$ and G. KANFANY ${ }^{1}$ \\ Kansas State University, Agricultural Research Center-Hays, KS 67601, USA \\ ${ }^{1}$ Institut Sénégalais de Recherches Agricoles (ISRA), Bambey, Senegal \\ 21'Institut d'Economie Rurale du Mali (IER), Cinzana, Mali \\ ${ }^{3}$ Institut National de la Recherche Agronomique du Niger (INRAN), Kollo, Niger \\ ${ }^{4}$ Institut de l'Environnement et Recherches Agricoles (INERA) CREAF de Kamboinse, \\ Ouagadougou, Burkina Faso \\ ${ }^{5}$ Institut National de la Recherche Agronomique du Niger (INRAN), Maradi, Niger \\ Corresponding author: ddserba@ksu.edu
}

(Received 2 April 2020; accepted 5 November 2020)

\begin{abstract}
Pearl millet (Pennisetum glaucum (L.) R. Br.) is a cereal crop vital for food security in West and Central Africa. Its byproducts also serve as fodder for livestock, especially during dry seasons. The objective of this study was to evaluate selected genotypes from West African pearl millet breeding programmes, for dual-purpose (grain and fodder) and elucidate prospects for future breeding. A total of 83 openpollinated varieties (OPVs), five composites, six landraces, one synthetic and five hybrids were evaluated at 14 environments in Burkina Faso, Mali, Niger and Senegal during the rainy seasons of 2015 and 2016. Combined analysis of data revealed significant differences among genotypes and prevalence of high genotype-by-environment interaction effects. Two stability analyses models consistently indicated that genotypes 10 (SMILBF10), 14 (SMILBF14) and 39 (SMILML5) were widely adaptable across the region. Plant height, panicle length and panicle yield showed significant positive correlations with grain yield; while days to flowering was negatively correlated. Positive correlation between grain and fodder yields indicate possibility for simultaneous improvement involving the two important traits. This result suggests that germplasm exchange and regionally integrated breeding programmes are important for the identification of widely adapted dual-purpose varieties of pearl millet, particularly in West African drylands.
\end{abstract}

Key Words: Genotype-by-environment, open-pollinated, Pennisetum glaucum

\section{RÉSUMÉ}

Le mil à chandelle (Pennisetum glaucum (L.) R. Br.) Est une céréale vitale pour la sécurité alimentaire en Afrique de l'Ouest et centrale. Ses sous-produits servent également de fourrage pour le bétail, en 
particulier pendant les saisons sèches. L'objectif de cette étude était d'évaluer des génotypes sélectionnés à partir des programmes de sélection du mil à chandelle d'Afrique de l'Ouest, pour $1^{\text {* }}$ usage double (céréales et fourrage) et d'élucider les perspectives de sélection dans le future. Les 83 variétés à pollinisation libre (OPV), cinq composites, six variétés locales, une synthétique et cinq hybrides ont été évalués dans les 14 environnements au Burkina Faso, au Mali, au Niger et au Sénégal pendant les saisons des pluies de 2015 et 2016. L' analyse combinée des données ont révélé des différences significatives entre les génotypes et la prévalence des effets élevés d'interaction génotypepar-environnement. Deux modèles d'analyses de stabilité ont systématiquement indiqué que les génotypes 10 (SMILBF10), 14 (SMILBF14) et 39 (SMILML5) étaient largement adaptables dans toute la région. La hauteur de la plante, la longueur de la panicule et le rendement de la panicule ont montré des corrélations positives significatives avec le rendement en grains; tandis que les jours avant la floraison étaient corrélés négativement. Une corrélation positive entre les rendements en céréales et en fourrage indique la possibilité d'une amélioration simultanée impliquant les deux caractères importants. Ce résultat suggère que l'échange de matériel génétique et les programmes de sélection intégrés au niveau régional sont importants pour l'identification de variétés à l' usage double largement adaptées de mil à chandelle, en particulier dans les zones arides d'Afrique de l'Ouest.

Mots Clés: Génotype par environnement, pollinisation libre, Pennisetum glaucum

\section{INTRODUCTION}

Pearl millet [(Pennisetum glaucum $($ L.) R. Br. $)$ syn. Cenchrus americanus] is a dryland cereal crop that plays important roles in subtropical and tropical regions of Africa. Archeological retrievals from different locations of West and Central Africa (D'Andrea and Casey, 2002; Fuller, 2007; Manning et al., 2011) and modern evolutionary biology studies using genomic tools, including resequencing of diverse genotypes ( Oumar et al., 2008; Burgarella et al., 2018), revealed that pearl millet originated and is domesticated in the southern periphery of the present Sahara desert in West Africa.

Pearl millet is a highly allogamous (Burton, 1974; Jauhar and Hanna, 1998) and landraces represent genetically heterozygous and heterogeneous open-pollinating populations. Considerable variation in plant morphology and seed characters are noticeable within and between different cultivars. Independent domestication events (Poncet et al., 1998), migrations from the centre of domestication, and outcrossing, including intercrossability with close wild relatives are attributable to the high genetic diversity in the germplasm. This huge genetic diversity is a vital resource for the breeding programmes aimed at improving the crop for adaptation, stress tolerance, desirable agronomic traits and yield performance.

Today, pearl millet is cultivated by millions of subsistence farmers as a staple food grain in arid and semi-arid regions of sub-Saharan Africa. It is often the only cereal crop in areas where drought and heat are the limiting factors for the growth and productivity of other cereals such as sorghum or maize. Climate-resilience physiological features of pearl millet at vegetative and reproductive stages make this crop well-suited to grow across a wide range of harsh climatic and edaphic conditions, including limited rainfall, high temperature, low soil fertility and high salinity (Varshney et al., 2017).

Variable onset of the rainy seasons, high inter annual rainfall variability, and intermittent droughts during the growing season characterise agricultural features of the Sahelian West Africa (Haussmann et al., 2012). Since pearl millet has low water demand and is drought tolerant, its yield can be leveraged for improvement under water-limited environments (Gowda et al., 2009). Pearl millet is a $\mathrm{C}_{4}$ grass with excellent photosynthetic efficiency and biomass production potential (Sanou et al., 2012), 
which additionally make it the most suitable crop for such harsh environmental conditions.

The area of land planted to pearl millet in the West and Central African region has steadily increased, but average productivity is still low, rarely reaching $1000 \mathrm{~kg} \mathrm{ha}^{-1}$ (Diack et al., 2017). This is attributed to limited genetic improvement, poor crop management practices and unfavourable socio-economic conditions of the subsistence farmers growing the crop. Farmers predominantly grow inherently low yielding landraces that are adaptable to specific agroclimatic niches and soil fertility conditions. Because of limited resource allocation, pearl millet improvement research is not in pace with the demand for the crop as well as the extent of production constraints. To develop and deliver improved varieties that withstand the biotic and abiotic stresses limiting productivity of the crop in the region are urgently needed. Therefore, a regionally integrated research strategy is encouraged for effective germplasm and information exchange for comparative advantage of the pearl millet breeding programmes in the region.

The objective of this study was to evaluate selected genotypes developed in West Africa for dual-purpose (grain and fodder) production and to elucidate the prospect of regional breeding.

\section{MATERIALS AND METHODS}

Experimental materials. A total of 100 pearl millet accessions, comprising of open pollinated varieties (OPV), composites and synthetic varieties, as well as experimental hybrids were used (Table 1) in this study. The accessions were contributed by pearl millet breeding programmes of Burkina Faso (34), Mali (20), Niger (23) and Senegal (23).

Testing locations. The test locations were systematically selected in each of the four countries, to represent both the Sahelian and Sudanian zones where pearl millet is predominantly grown. The rainfall characteristics of the test locations during 2015 and 2016 growing seasons are presented in Table 2; the only exception was that of N'Tarla (Mali) which had no weather data.

The field trials were conducted at seven locations in the four countries; during 2015 and 2016 growing seasons. The test locations were Dori in Burkina Faso, Cinzana and N'Tarla in Mali, Bengou and Maradi in Niger, and Bambey and Nioro in Senegal. The experiment was laid out in a randomised complete block design (RCBD), with two replications. Each accession was planted in two-row plots of $4 \mathrm{~m}$ and $0.8 \mathrm{~m}$ inter- and intra-row spacings. All the recommended agronomic practices at each location were applied. Data were collected on days to flowering (DFL), plant height (PHT), number of panicles per plot (NPL), panicle length (PLG), panicle yield (PNY), grain yield (GYD), and fodder yield (FYD).

Statistical analysis. Phenotypic data were analysed using the SAS 9.4 ® statistical programme (SAS Institute, Cary, NC) and R package called Performance Analytics. Normality for each trait was determined using the univariate procedure. An initial analysis of variance was performed for each environment to verify the existence of differences among the accessions. The homogeneity between residual variances was determined, and a combined analysis of variance was used to test the genotype and environment effects and the magnitude of the $\mathrm{G} \times \mathrm{E}$ interaction. A generalised linear model was used to partition the variances into year, location, replication, genotype and their interaction effects for each trait. Statistical significance was assessed at 5\% probability level, unless indicated otherwise.

Stability analysis. Two stability analysis models were used to determine grain yield performance of the genotypes across environments. Both the Additive Main Effects and Multiplicative Interactions (AMMI) analysis (Gauch and Zobel, 1988) and Eberhart and Russell stability parameters (Eberhart and 
TABLE 1. List of accessions used in the study with their pedigree, and source country

\begin{tabular}{|c|c|c|c|c|}
\hline No & Entry & Designation & Variety (type)* & Country \\
\hline 1 & SMILBF1 & PE05887 & Varexp(OPV) & Burkina Faso \\
\hline 2 & SMILBF2 & KalpelgaxPE03922 & $\operatorname{Var} \exp (\mathrm{OPV})$ & Burkina Faso \\
\hline 3 & SMILBF3 & PE0437xPE00515 & $\operatorname{Var} \exp (\mathrm{OPV})$ & Burkina Faso \\
\hline 4 & SMILBF4 & PE00397xPE00515 & Varexp(OPV) & Burkina Faso \\
\hline 5 & SMILBF5 & MISARI-1 & OPV & Burkina Faso \\
\hline 6 & SMILBF6 & MISARI-2 & OPV & Burkina Faso \\
\hline 7 & SMILBF7 & PE05578C1 & Varexp(OPV) & Burkina Faso \\
\hline 8 & SMILBF8 & PE08030C0 & Composite $\mathrm{C} 0$ & Burkina Faso \\
\hline 9 & SMILBF9 & PE08011 C0 & Composite $\mathrm{C} 0$ & Burkina Faso \\
\hline 10 & SMILBF10 & Local Djibasso C0 & Composite $\mathrm{C} 0$ & Burkina Faso \\
\hline 11 & SMILBF11 & Sahel 22 C0 & Composite $\mathrm{C} 0$ & Burkina Faso \\
\hline 12 & SMILBF12 & PE00967C0 & Composite $\mathrm{C} 0$ & Burkina Faso \\
\hline 13 & SMILBF13 & IKMP 1 & OPV & Burkina Faso \\
\hline 14 & SMILBF14 & IKMP 5 & OPV & Burkina Faso \\
\hline 15 & SMILBF15 & IKMV8201 & OPV & Burkina Faso \\
\hline 16 & SMILBF16 & PE01203 X PE05980-R3 & Varexp(OPV) & Burkina Faso \\
\hline 17 & SMILBF17 & PE02987 X ICMV IS 92222 & Varexp(OPV) & Burkina Faso \\
\hline 18 & SMILBF18 & PE02853xPE00404R3 & $\operatorname{Var} \exp (\mathrm{OPV})$ & Burkina Faso \\
\hline 19 & SMILBF19 & Group1 & Varexp(OPV) & Burkina Faso \\
\hline 20 & SMILBF20 & Group3 & Varexp(OPV) & Burkina Faso \\
\hline 21 & SMILBF21 & Group4 & Varexp(OPV) & Burkina Faso \\
\hline 22 & SMILBF22 & Group6 & Varexp(OPV) & Burkina Faso \\
\hline 23 & SMILBF23 & Groupe7 & Varexp(OPV) & Burkina Faso \\
\hline 24 & SMILBF24 & Local kamboinse & local & Burkina Faso \\
\hline 25 & SMILBF25 & Local Nahartenga & local & Burkina Faso \\
\hline 26 & SMILBF26 & GBxMORO & Varexp(OPV) & Burkina Faso \\
\hline 27 & SMILBF27 & PE00437XРE00273 & Varexp(OPV) & Burkina Faso \\
\hline 28 & SMILBF28 & PE00437XICMVIS92222 & $\operatorname{Var} \exp (\mathrm{OPV})$ & Burkina Faso \\
\hline 29 & SMILBF29 & PE00397XPE00404 & Varexp(OPV) & Burkina Faso \\
\hline 30 & SMILBF30 & PE02987XPE05347 & Varexp(OPV) & Burkina Faso \\
\hline 31 & SMILBF31 & PE053/73 & Parent R(OPV) & Burkina Faso \\
\hline 32 & SMILBF32 & IBMV8402 & OPV & Burkina Faso \\
\hline 33 & SMILBF33 & ICMVIS89305 & OPV & Burkina Faso \\
\hline 34 & SMILBF34 & PE05539 & Varexp(OPV) & Burkina Faso \\
\hline 35 & SMILML1 & CzSyn 00-06 & Synth (OPV) & Mali \\
\hline 36 & SMILML2 & SoSat & OPV & Mali \\
\hline 37 & SMILML3 & CzSyn 00-01 & Synth (OPV) & Mali \\
\hline 38 & SMILML4 & CzSyn 03-10 & Synth (OPV) & Mali \\
\hline 39 & SMILML5 & CzSyn 00-02 & Synth (OPV) & Mali \\
\hline 40 & SMILML6 & Cr Toroniou HTC & hybrid & Mali \\
\hline 41 & SMILML7 & CzToroniou HTC Aristé & hybrid & Mali \\
\hline 42 & SMILML8 & Cz Maïwa HTC aristé & hybrid & Mali \\
\hline 43 & SMILML9 & Toroniou C1 & OPV & Mali \\
\hline 44 & SMILML10 & Sanioba 03 & OPV & Mali \\
\hline 45 & SMILML11 & Indiana 05 & OPV & Mali \\
\hline
\end{tabular}


TABLE 1. Contd.

\begin{tabular}{|c|c|c|c|c|}
\hline No & Entry & Designation & Variety (type)* & Country \\
\hline 46 & SMILML12 & Djiguifa & OPV & Mali \\
\hline 47 & SMILML13 & CzMil Aristé & Synth (OPV) & Mali \\
\hline 48 & SMILML14 & NKO/TC1 & OPV & Mali \\
\hline 49 & SMILML15 & Boboni & OPV & Mali \\
\hline 50 & SMILML16 & Cz Syn 0311 & Synth (OPV) & Mali \\
\hline 51 & SMILML17 & 16 & $\operatorname{Var} \exp (\mathrm{OPV})$ & Mali \\
\hline 52 & SMILML18 & PEO6001 & OPV & Mali \\
\hline 53 & SMILML19 & PE02983 & OPV & Mali \\
\hline 54 & SMILML20 & PE05607 & OPV & Mali \\
\hline 55 & SMILNG1 & IP8688 & $\operatorname{Var} \exp (\mathrm{OPV})$ & Niger \\
\hline 56 & SMILNG2 & PE02945 & $\operatorname{Var} \exp (\mathrm{OPV})$ & Niger \\
\hline 57 & SMILNG3 & B9-Tabi & OPV & Niger \\
\hline 58 & SMILNG4 & PE02831 & $\operatorname{Var} \exp (\mathrm{OPV})$ & Niger \\
\hline 59 & SMILNG5 & PE00040 & $\operatorname{Var} \exp (\mathrm{OPV})$ & Niger \\
\hline 60 & SMILNG6 & PE05913 & $\operatorname{Var} \exp (\mathrm{OPV})$ & Niger \\
\hline 61 & SMILNG7 & PE00626 & $\operatorname{Var} \exp (\mathrm{OPV})$ & Niger \\
\hline 62 & SMILNG8 & PE05346 & $\operatorname{Var} \exp (\mathrm{OPV})$ & Niger \\
\hline 63 & SMILNG9 & PE01491 & $\operatorname{Var} \exp (\mathrm{OPV})$ & Niger \\
\hline 64 & SMILNG10 & PE02898 & $\operatorname{Var} \exp (\mathrm{OPV})$ & Niger \\
\hline 65 & SMILNG11 & PE02603 & $\operatorname{Var} \exp (\mathrm{OPV})$ & Niger \\
\hline 66 & SMILNG12 & PE05387 & $\operatorname{Var} \exp (\mathrm{OPV})$ & Niger \\
\hline 67 & SMILNG13 & PE00437 & $\operatorname{Var} \exp (\mathrm{OPV})$ & Niger \\
\hline 68 & SMILNG14 & PE00456 & $\operatorname{Var} \exp (\mathrm{OPV})$ & Niger \\
\hline 69 & SMILNG15 & PE02983 & $\operatorname{Var} \exp (\mathrm{OPV})$ & Niger \\
\hline 70 & SMILNG16 & PE08039 & $\operatorname{Var} \exp (\mathrm{OPV})$ & Niger \\
\hline 71 & SMILNG18 & GAMOGI & Landrace (OPV) & Niger \\
\hline 71 & SMILNG17 & HKP-GMS x MORO & OPV x Landrace & Niger \\
\hline 73 & SMILNG19 & GAxHKB & Landrace x OPV & Niger \\
\hline 74 & SMILNG20 & BOUDOUMA & Landrace (OPV) & Niger \\
\hline 75 & SMILNG21 & TTCHININ-BIJINI & Landrace (OPV) & Niger \\
\hline 76 & SMILNG22 & HKB & OPV & Niger \\
\hline 77 & SMILNG23 & H80-10GR & OPV & Niger \\
\hline 78 & SMILSG1 & S1-516 & Landrace (OPV) & Senegal \\
\hline 79 & SMILSG2 & S1-308 & Landrace (OPV) & Senegal \\
\hline 80 & SMILSG3 & S1-433 & Landrace (OPV) & Senegal \\
\hline 81 & SMILSG4 & S1-86 & Landrace (OPV) & Senegal \\
\hline 82 & SMILSG5 & S1-619 & Landrace (OPV) & Senegal \\
\hline 83 & SMILSG6 & S1-328 & Landrace (OPV) & Senegal \\
\hline 84 & SMILSG7 & S1-55 & Landrace (OPV) & Senegal \\
\hline 85 & SMILSG8 & S1-59 & Landrace (OPV) & Senegal \\
\hline 86 & SMILSG9 & S1-126 & Landrace (OPV) & Senegal \\
\hline 87 & SMILSG10 & S1-215 & Landrace (OPV) & Senegal \\
\hline 88 & SMILSG11 & S1-416 & Landrace (OPV) & Senegal \\
\hline 89 & SMILSG12 & S1-523 & Landrace (OPV) & Senegal \\
\hline 90 & SMILSG13 & S1-510 & Landrace (OPV) & Senegal \\
\hline
\end{tabular}


TABLE 1. Contd.

\begin{tabular}{lllll}
\hline No & Entry & Designation & Variety (type)* & Country \\
\hline 91 & SMILSG14 & S1-515 & Landrace (OPV) & Senegal \\
92 & SMILSG15 & S1-423 & Landrace (OPV) & Senegal \\
93 & SMILSG16 & S1-28 & Landrace (OPV) & Senegal \\
94 & SMILSG17 & S1-53 & Landrace (OPV) & Senegal \\
95 & SMILSG18 & S1-527 & Landrace (OPV) & Senegal \\
96 & SMILSG19 & S1-323 & Landrace (OPV) & Senegal \\
97 & SMILSG20 & S1-169 & Landrace (OPV) & Senegal \\
98 & SMILSG21 & S1-620 & Landrace (OPV) & Senegal \\
99 & SMILSG22 & S1-633 & Landrace (OPV) & Senegal \\
100 & SMILSG23 & THIALACKZ & Synth OPV & Senegal \\
\hline
\end{tabular}

TABLE 2. Monthly total rainfall (mm) of the trial locations during 2015 and 2016 growing seasons at the different study sites in west and central African countries

\begin{tabular}{lrrrrrrrr}
\hline Location & Year & May & June & July & August & September & October & $\begin{array}{r}\text { Total } \\
\text { rainy } \\
\text { days }\end{array}$ \\
& & & & & & & & \\
Maradi, Niger & 2015 & 0.9 & 34.4 & 168.1 & 228.6 & 64.9 & 0.0 & 35 \\
& 2016 & 24.0 & 49.0 & 175.0 & 210.5 & 90.5 & 0.0 & 37 \\
Bengou, Niger & 2015 & 19.3 & 53.5 & 180.2 & 277.3 & 236.0 & 30.0 & 56 \\
& 2016 & 97.5 & 101.3 & 163.3 & 272.9 & 123.1 & 17.0 & 74 \\
Bambey, Senegal & 2015 & 0.0 & 0.0 & 124.0 & 281.1 & 265.6 & 21.5 & 39 \\
& 2016 & - & 0.0 & 116.4 & 136.9 & 150.0 & 9.2 & 34 \\
Nioro, Senegal & 2015 & 0.0 & 1.7 & 142.6 & 363.3 & 342.3 & 164.6 & 55 \\
& 2016 & 0.5 & 21.3 & 240.3 & 327.4 & 314.2 & 13.5 & 52 \\
Dori, Burkina Faso & 2015 & 0 & 76 & 83.5 & 48.5 & 2.5 & 0 & 8 \\
& 2016 & 32.5 & 65.5 & 139 & 160.5 & 67 & 6.5 & 27 \\
Cinzana, Mali $\dagger$ & 2015 & 40 & 104 & 182 & 234 & 132 & 38 & - \\
& 2016 & 40 & 104 & 182 & 234 & 132 & 38 & - \\
\hline
\end{tabular}

${ }^{\dagger}$ Mean rainfall data of 10 years (2005 to 2015) at Cinzana, Mali. Local agroclimatic data was not available for N'tarla in Mali

Russell, 1966) were conducted using GEA-R (Genotype $\mathrm{x}$ Environment Analysis with R for Windows) Version 4.1 (Pacheco et al., 2018).

AMMI was used to adjust the main or additive genotype and environmental effects by analysis of variance, in addition to the adjustment of the multiplicative effects for the
$\mathrm{G} \times \mathrm{E}$ interaction by principal component analysis. The multi-environment performance analysis was conducted according to the following AMMI statistical model:

$\mathrm{Y}_{\mathrm{ge}}=\mu+\alpha_{\mathrm{g}}+\beta_{\mathrm{e}}+\sum_{\mathrm{n}} \lambda_{\mathrm{n}} \gamma_{\mathrm{gn}} \delta_{\mathrm{en}}+\mathrm{p}_{\mathrm{ge}} \quad($ Gauch, 1988) 
Where:

$\mathrm{Y}_{\mathrm{ge}}$ is the yield of genotype $\mathrm{g}$ in environment $\mathrm{e}$, ì is the grand mean, $\alpha_{\mathrm{g}}$ is the genotype deviation from the grand mean, $\beta_{\mathrm{e}}$ is the environment deviation from the grand mean, $\lambda_{n}$ is the singular value for the interaction principal component and correspondingly $\lambda_{2 n}$ is its eigenvalue, $\gamma_{\mathrm{gn}}$ is the eigenvector value for genotype $\mathrm{g}$ and component $\mathrm{n}, \delta_{\mathrm{en}}$ is the eigenvector value for environment e and component $\mathrm{n}$, with both eigenvectors scaled as unit vectors, and $\mathrm{p}_{\mathrm{ge}}$ is the residual.

The interaction scores are scaled as $\lambda_{0.5 \mathrm{n}} \gamma_{\mathrm{gn}}$ and $\lambda_{0.5 n} \delta_{\text {en }}$ so that their products estimate interactions without the need of yet another multiplication by $\lambda$.

The sum of squares of the $\mathrm{G} \times \mathrm{E}$ interaction for grain yield was divided into a $n$ singular axis or interaction principal component axis (IPCA), which reflects the standard portion in which each axis corresponded to a particular AMMI model. Selection of a model that best describes the GEI was based on the $F_{R}$ test, as proposed by Cornelius et al. (1992) to determine how many IPCs are significant. When the $F_{R}$ test is significant, it suggests that there is at least one more multiplicative term in addition to the terms already fitted.

Furthermore, AMMI's stability value (ASV) was calculated in order to rank genotypes in terms of stability using the formula suggested by Purchase (Purchase et al., 2000). The smaller ASV indicates a more stable genotype across environments; and the larger the ASV the more specifically adapted the genotype is to a certain environment.

The Eberhart and Russell stability analysis model states as follows:

$\gamma_{\mathrm{ij}}=\mu+\mathrm{d}_{\mathrm{i}}+\varepsilon_{\mathrm{j}}+\mathrm{g}_{\mathrm{ij}}+\varepsilon_{\mathrm{ij}}$ (Eberhart and Russell,

Where:

$\gamma_{i j}$ is the yield estimate of the $i^{\text {th }}$ genotype in the $j^{\text {th }}$ environment, $\mu$ is grand mean of overall genotypes and environments; $\mathrm{d}_{\mathrm{i}} \mathrm{is}$ an additive genetic contribution of the $\mathrm{i}^{\text {th }}$ genotype; $\varepsilon_{\mathrm{j}}$ is additive environmental contribution of the $j^{\text {th }}$ environment; $g_{i j}$ is the genotype-environmental interaction of the $i^{\text {th }}$ genotype in the $j^{\text {th }}$ environment; $\varepsilon_{i j}$ is experimental error of the $i^{\text {th }}$ line in the $\mathrm{j}^{\text {th }}$ environment.

\section{RESULTS AND DISCUSSION}

\section{Agronomic and yield traits}

Days to $50 \%$ flowering. Days to $50 \%$ flowering (DFL) for accessions revealed that SMILSG10 took the longest time (81 days) to flower; followed by SMILNG4, SMILSG19, SMILNG12, and SMILNG13 in that order. On the other hand, 22 accessions took less than 60 days to flower. The early flowering genotypes were SMILBF15 (56 days), SMILNG20 (56 days), and SMILNG17 (58 days). Mean DFL was less than 60 days at Bambey in 2016, Nioro in 2016, and Dori in 2016. Cinzana in 2015, N'tarla in 2015, and Maradi in 2016 had longer mean DFL and several genotypes 100 days (data not presented). Pearl millet landraces are diverse in morphology, cycle duration, yield potential, and stress tolerance.

Based on days to flowering, pearl millet cultivars grown in West Africa are predominantly categorised into Souna (earlyflowering) and Sanio (late-flowering) morphotypes (Dussert et al., 2015). This phenological diversity contributed to the adaptation of the crop to the Sahel zone, which is characterised by inter- and intra-annual rainfall fluctuations. The short seasoned and photoperiod insensitive Souna morphotypes are adaptable to the short rainy season of the Sahel. The late flowering Sanio are more sensitive to photoperiod and adapted to the Sudanian zone, and have higher grain, as well as fodder yield potential than early-flowering ones (Haussmann et al., 2007). Therefore, flowering time is an important trait in pearl millet adaptation to climate variability and genetic yield potential. 
The flowering date of the genotypes was shortened in the severe drought conditions at Bambey in 2016, Nioro in 2016, and Dori in 2016. In Maradi in 2016, Cinzana in 2015, and $\mathrm{N}$ 'tarla in 2015 longer mean DFL was recorded probably because of better rainfall amount and distribution. This result indicates that the long duration genotypes, with high biomass production potential, have the drought escape mechanism. The drought avoidance mechanism that delays the development of tillers to prolong flowering time is more prevalent in the short duration Souna ecotypes (Winkel et al., 1997).

Plant height. There were significant differences between years, among locations and accessions for plant height (PHT) and interaction effects, except for location $x$ genotype (Table 3). PHT was significantly greater in $2015(276 \mathrm{~cm})$ than $2016(247 \mathrm{~cm})$. Location-wise, plant height was high at Maradi (292) and Bengou (304) in 2015; while it was short at Dori $(206 \mathrm{~cm})$ and N'tarla $(237 \mathrm{~cm})$ in 2015 (data not presented). The tallest overall PHT was in SMILNG15 $(299 \mathrm{~cm})$; while the shortest was SMILBF32 $(217 \mathrm{~cm})$.

Plant height is a growth attribute directly linked with the productive potential of a genotype, especially in terms of fodder yield (Maleko et al., 2019). Reports indicate significant differences among pearl millet cultivars in respect to plant height (Amodu et al., 2007; Hassan et al., 2014). In spite of the inherent genetic differences prevalent among the genotypes, the results of this study revealed that plant height was highly influenced by the environment. The dry conditions in the Sahel significantly reduced plant height of the genotypes studied.

Panicle length. Panicle length (PLG) was significant across environments, genotypes and interactions, except for location $x$ genotype (Table 2). Accessions with the longest panicle included SMILNG21,

TABLE 3. Combined analysis of variance for agronomic and yield traits of 100 pearl millet accessions grown at multi-environments in Burkina Faso, Mali, Niger and Senegal during 2015 and 2016

\begin{tabular}{|c|c|c|c|c|c|c|c|c|}
\hline \multirow[t]{2}{*}{ Source } & \multirow[t]{2}{*}{ DF } & \multicolumn{6}{|c|}{ F-value } & \multirow[b]{2}{*}{ FYD } \\
\hline & & DFL & PHT & PLG & NPL & PNY & GYD & \\
\hline Year $(\mathrm{Y})$ & 1 & $88.9 * *$ & $568.06 * *$ & $4.82 *$ & $218.44 * *$ & $1293.15^{* *}$ & $346.77 * *$ & $345.53 * *$ \\
\hline Location (L) & 6 & $457.76 * *$ & $190.78 * *$ & $19.87 * *$ & $262.01 * *$ & $420.83 * *$ & $110.83 * *$ & $331.27 * *$ \\
\hline Replication & 1 & $0.25 \mathrm{~ns}$ & $1.1 \mathrm{~ns}$ & $3.88 \mathrm{~ns}$ & $0.02 \mathrm{~ns}$ & $4.12 *$ & $0.38 \mathrm{~ns}$ & $34.53 * *$ \\
\hline Genotype (G) & 99 & $31.01 * *$ & $10.58 * *$ & $25.4 * *$ & $5.41 * *$ & $2.42 * *$ & $4.54 * *$ & $3.92 * *$ \\
\hline $\mathrm{YxL}$ & 6 & $200.75^{* *}$ & $77.29 * *$ & $22.32 * *$ & $60.74 * *$ & $223.41 * *$ & $69.5^{* *}$ & $28.41 * *$ \\
\hline$Y \times G$ & 98 & $8.57 * *$ & $2.65 * *$ & $1.58 * *$ & $2.12 * *$ & $1.89 * *$ & $1.86^{* *}$ & $2.32 * *$ \\
\hline $\mathrm{L} x \mathrm{G}$ & 592 & $1.78 * *$ & $1.09 \mathrm{~ns}$ & $1.07 \mathrm{~ns}$ & $1.48^{* *}$ & $1.42 * *$ & $2.3 * *$ & $1.2 * *$ \\
\hline Y x L x G & 573 & $1.34 * *$ & $0.96 \mathrm{~ns}$ & $1.15^{*}$ & $1.15^{*}$ & $1.48 * *$ & $1.4 * *$ & $1.18^{*}$ \\
\hline Error DF & & 1346 & 1347 & 1339 & 1298 & 1196 & 1348 & 1030 \\
\hline $\mathrm{R}^{2}$ & & 0.88 & 0.78 & 0.76 & 0.78 & 0.85 & 0.76 & 0.81 \\
\hline CV $(\%)$ & & 7.8 & 12.0 & 19.8 & 30.4 & 32.3 & 33.8 & 40.9 \\
\hline Root MSE & & 5.1 & 31.3 & 8.6 & 15076.7 & 1003.9 & 523.5 & 1499.7 \\
\hline Mean & & 65 days & $262 \mathrm{~cm}$ & $43 \mathrm{~cm}$ & 49614 & $3109 \mathrm{~kg} \mathrm{ha}^{-1}$ & $1548 \mathrm{~kg} \mathrm{ha}^{-1}$ & $3664 \mathrm{~kg} \mathrm{ha}^{-1}$ \\
\hline
\end{tabular}

$\mathrm{DFL}=$ Days to $50 \%$ flowering; $\mathrm{PHT}=$ Plant height $(\mathrm{cm}) ; \mathrm{PLG}=$ Panicle length $(\mathrm{cm}) ; \mathrm{NPL}=$ Number of panicles per hectare; $\mathrm{PNY}=$ Panicle yield $\left(\mathrm{kg} \mathrm{ha}^{-1}\right) ; \mathrm{GYD}=$ Grain yield $\left(\mathrm{kg} \mathrm{ha}^{-1}\right) ;$ and $\mathrm{FYD}=$ Fodder yield $\left(\mathrm{kg} \mathrm{ha}^{-1}\right) ; \mathrm{DF}=$ degrees of freedom, $\mathrm{CV}=$ Coefficient of variation; MSE = Mean Square of Error; ns = not significant; *, **, = significant at $\mathrm{P}<0.05$ and $\mathrm{P}<0.01$ probability levels, respectively 
SMILSG1 and SMILSG12, with mean PLG values of 69,63 and $62 \mathrm{~cm}$, respectively. On the contrary, eight accessions (SMILBF26, SMILNG20, SMILBF25, SMILBF2, SMILBF24, SMILBF15, SMILNG3 and SMILML2) had low PLG values, which ranged from 28 to $33 \mathrm{~cm}$.

Panicle length is one of the major yield components in pearl millet (Ouendeba et al., 1995; Obeng et al., 2012) and landraces grown in West Africa are diverse in panicle size (Wilson et al., 1990; Ouendeba et al., 1995; Upadhyaya et al., 2017). The diversity available in the landraces for this important yield component and its correlation with grain and fodder yields (Diack et al., 2017) can be leveraged for dual-purpose cultivar development in West Africa.

Number of panicles. There were significant differences among years, locations, genotypes and their interactions for number of panicles (NPL) per hectare (Table 3). The result showed that SMILBF25, followed by SMILBF13, SMILBF24 and SMILBF30 produced significantly $(\mathrm{P}<0.001)$ higher mean NPL (64497, 62640, 62230 and 60908 panicles per hectare, respectively). However, two of these accessions (SMILBF25 and SMILBF24) had short panicles. SMILNG4 and SMILNG16 showed the lowest mean NPL of 34473 and 34654 per hectare. Lower NPL values were observed at Dori and N'tarla, which reflected limited tillering attributable to drought stress. Number of panicles (NPL) per unit area is an indicative of the stand count and productive tillers in pearl millet, and has direct effect on both grain and fodder yields. Moreover, genotypes with good tillering capacity and uniform maturity are important in bolstering both grain and fodder yields. A previous report indicates that competition for light between axes, especially during stem elongation stage suppress the growth of productive tillers (Oosterom et al., 2001). Therefore, enhancing the number of productive tillers depends on leaf area profiles of the main shoots and tillers. Tillering is also a very plastic trait that can adapt to environmental conditions and crop management. Selection of genotypes with good stand establishment, early uniform tiller formation, and uniform maturity may boost dual-purpose productivity of the crop.

Panicle yield. Panicle yield (PNY), the main selection index for grain yield in pearl millet (Haryanto et al., 1998), was highly significant across the environments, genotypes and their interaction effects for PNY (Table 3). Accessions with significantly high PNY included SMILNG9 (3734 $\left.\mathrm{kg} \mathrm{ha}^{-1}\right)$ and SMILML6 (3600 kg ha-1). On the other hand, the lowest PNY values were observed for SMILNG3 (2137 kg ha') and SMILNG1 (2206 $\mathrm{kg} \mathrm{ha}^{-1}$ ) that also had short PLG.

Panicle yield comprises of the individual panicle size and number of panicles per unit area (Fageria, 2007). Therefore, the length and diameter of the panicle, number of panicles, and grain filling, as well as seed size and plumpness are reflected in panicle yield. Panicle yield was reported to show highly positive response to selection with high heritability (Haryanto et al., 1998). Therefore, in selection for dual-purpose varieties, due consideration should be given to panicle yield as a favourable trait.

Grain yield. Grain yield (GYD) was significant between years, across locations, among genotypes and their interactions (Table $3)$. The accession with highest mean GYD was SMILBF9 (1989 kg ha-1), followed by SMILML6 (1975 kg ha-1) and SMILSG1 (1904 $\left.\mathrm{kg} \mathrm{ha}^{-1}\right)$. Fourteen other accessions had mean GYD greater than $1800 \mathrm{~kg} \mathrm{ha}^{-1}$. On the other hand, 11 accessions had overall mean GYD less than $1300 \mathrm{~kg} \mathrm{ha}^{-1}$.

All the interaction effects were also significant, implying the difficulty to select the genotypes based on their mean performance per se. This performance outcome calls for stability analysis to select the most adaptable genotype with stable performance across environments or select narrowly adapted genotypes for a specific environment. 
Otherwise, grain yield improvement and its stable performance across locations and over years are important in plant breeding and thus needs greater exploration to benefit different national breeding programmes in the Sahel region.

Fodder yield. Fodder yield (FYD) also showed significant differences between years, across locations, among genotypes and their interactions (Table 3). Overall, two locations in Niger (Maradi and Bengou) showed higher FYD than the other locations. Accessions SMILNG11, SMILBF5, SMILNG15, SMILML16 and SMILBF12 had significantly higher overall FYD that ranged from 4620 to $4648 \mathrm{~kg} \mathrm{ha}^{-1}$. On the contrary, there were genotypes with FYD lower than $2000 \mathrm{~kg} \mathrm{ha}^{-1}$.

Previous studies showed prevalence of significant differences among pearl millet landraces in total biomass, grain and stover yields (Yadav and Bidinger, 2008); all of which are vital resources for crop improvement as it offers an opportunity for selection of a desired genotype as a potential cultivar. The higher the extent of genetic variability in the breeding population, the more likelihood of improvement for targeted traits. Therefore, landraces may serve as the main sources of variation for breeding dual-purpose varieties and other desirable traits. Furthermore, the landraces showed significant heterosis for biomass, grain and stover yields (Yadav and Bidinger, 2008). Thus, landrace-based topcross hybrids may be a better alternative to the OPV in dualpurpose variety development in the region.

$\mathbf{G} \times \mathbf{E}$ interaction and yield stability. The combined analysis of variance (Table 3 ) showed presence of highly significant GEI for yield that does not permit to define overall ranking of varieties across environments. The result of performance evaluation at seven locations, for two year (14 total environments) across the region, indicated evidence of widely adaptable genotypes among the accessions. There were also genotypes with specific adaptation, as their yield performance was favoured in certain environments mainly in relatively due to favourable rainfall conditions. Since GEI was high, the stability of the test genotypes was estimated by two yield stability parameters, namely Eberhart and Russell (Eberhart and Russell, 1966) and the Additive Main effects and Multiplicative Interaction (AMMI) model (Gauch, 1988) and the outcomes are discussed in the following sections.

Eberhart and Russell stability analysis. In this stability analysis, the sum of square due to $\mathrm{G} \times \mathrm{E}$ were apportioned into individual genotypes (X-i), regression of environmental means (bi) and deviation from regression $\left(\mathrm{S}^{2} \mathrm{~d}\right)$. The regression coefficients (bi) and mean square deviation from regression $\left(\mathrm{S}^{2} \mathrm{~d}\right)$ were used to define genotype stability. The Eberhart and Russell stability analysis and the graph of regression of environmental means (bi) against the deviation from regression commonly called coefficient of determination $\left(\mathrm{S}^{2} \mathrm{~d}\right)$ (Fig. 1), identified 10 genotypes which had general adaptability (no significant change in their yields as a result of changes in climatic conditions in the test environments). These were entries number 10 (SMILBF10), 14 (SMILBF14), 39 (SMILML5), 57 (SMILNG3), 58 (SMILNG4), 65 (SMILNG11), 76 (SMILNG22), 78 (SMILSG1), 79 (SMILSG2), and 94 (SMILSG17). Among these generally adaptable genotypes, SMILBF10 and SMILBF14 were contributed by Burkina Faso. SMILSG1, SMILSG2 and SMILSG17 by Senegal; while SMILNG3, SMILNG4, SMILNG11 and SMILNG22 were from Niger, and SMILML5 from Mali breeding programmes. From this result, we deduce that regional germplasm exchange is vital in identifying widely adaptable pearl millet cultivars in the region.

AMMI analysis. The environment effect explained almost a third $(32.5 \%)$ of the variation in grain yield performance across environments (Table 4). Genotype explained only $10.7 \%$ of the variation; while the G x E 


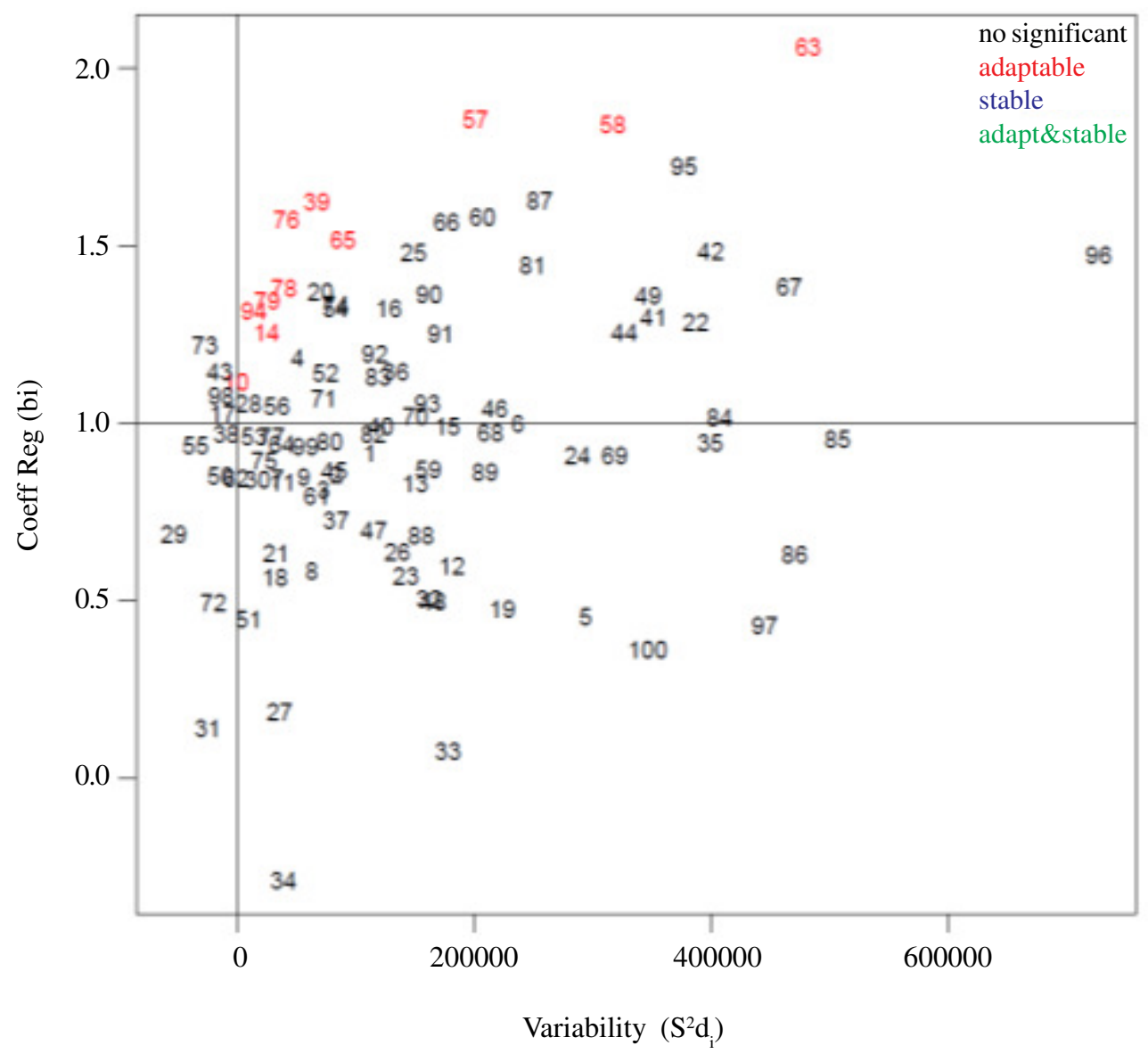

Figure 1. Eberhart and Russell stability plot of 100 pearl millet genotypes based on regression (bi) and deviations from regression (S2di). Entries with the red color are identified as widely adaptable.

component of the variation accounted for $56.8 \%$. Though the first three axes explained a total of $55.10 \%$ of the interaction effect for grain yield, seven PCs were significant and accounted for $81.7 \%$ of the interaction sum of squares. This implies that there are multiple factors contributing to the interaction effects. The PCA analysis indicated year-to-year that variations in those locations, to the level it affects the yield performance of the genotypes.

On the basis of Factor 1, test locations Nioro and Bambey consistently belonged to a similar category, but differed on the basis of Factor 2 (Fig. 2). Genotypes such as 84 (SMILSG7), 85 (SMILSG8), 93 (SMILSG16), 95 (SMILSG18), and 97
(SMILSG20) better adapted to Nioro and Bambey. On the other hand, Dori, Bengou, Maradi, N'tarla and Cinzana were classified as similar growing environments. Genotypes 8 (SMILBF8), 23 (SMILBF23), 29 (SMILBF29), 35 (SMILML1) and 46 (SMILML12) were better adapted to this set of locations.

In the resulting Factor 1 against grain yield biplot, contemporarily main effects (genotypes and environments average yields) and interaction were distributed throughout the four sections of the biplot (Fig. 3). The GGE biplot revealed that genotype such as 40 (SMILML6), 41 (SMILML7), 78 (SMILSG1) and 91 (SMILSG14) had overall high mean grain yield and responsive performance as they 
TABLE 4. Analysis of variance for pearl millet grain yield and G X E partitioning according to the Additive Main Effect and Multiplicative Interaction (AMMI) analysis

\begin{tabular}{lrcccc}
\hline Source & DF & $\begin{array}{c}\text { Variation } \\
\text { explained }(\%)\end{array}$ & $\begin{array}{c}\text { \% explained } \\
\text { (cumulative) }\end{array}$ & F-Ration & P value \\
\hline Environment (E) & 13 & 32.5 & 32.5 & 116.65 & 0.00 \\
Genotype (G) & 99 & 10.7 & 43.2 & 5.06 & 0.00 \\
EXG & 1287 & 56.8 & 100.0 & 2.06 & 0.00 \\
PC1 & 111 & 25.5 & 25.5 & 6.09 & 0.00 \\
PC2 & 109 & 16.4 & 41.9 & 3.99 & 0.00 \\
PC3 & 107 & 13.2 & 55.1 & 3.29 & 0.00 \\
PC4 & 105 & 9.0 & 64.1 & 2.27 & 0.00 \\
PC5 & 103 & 6.9 & 71.0 & 1.79 & 0.00 \\
PC6 & 101 & 5.7 & 76.7 & 1.49 & 0.00 \\
PC7 & 99 & 5.0 & 81.7 & 1.34 & 0.02 \\
Residuals & 1399 & 0.0 & 0.0 & - & - \\
\hline
\end{tabular}

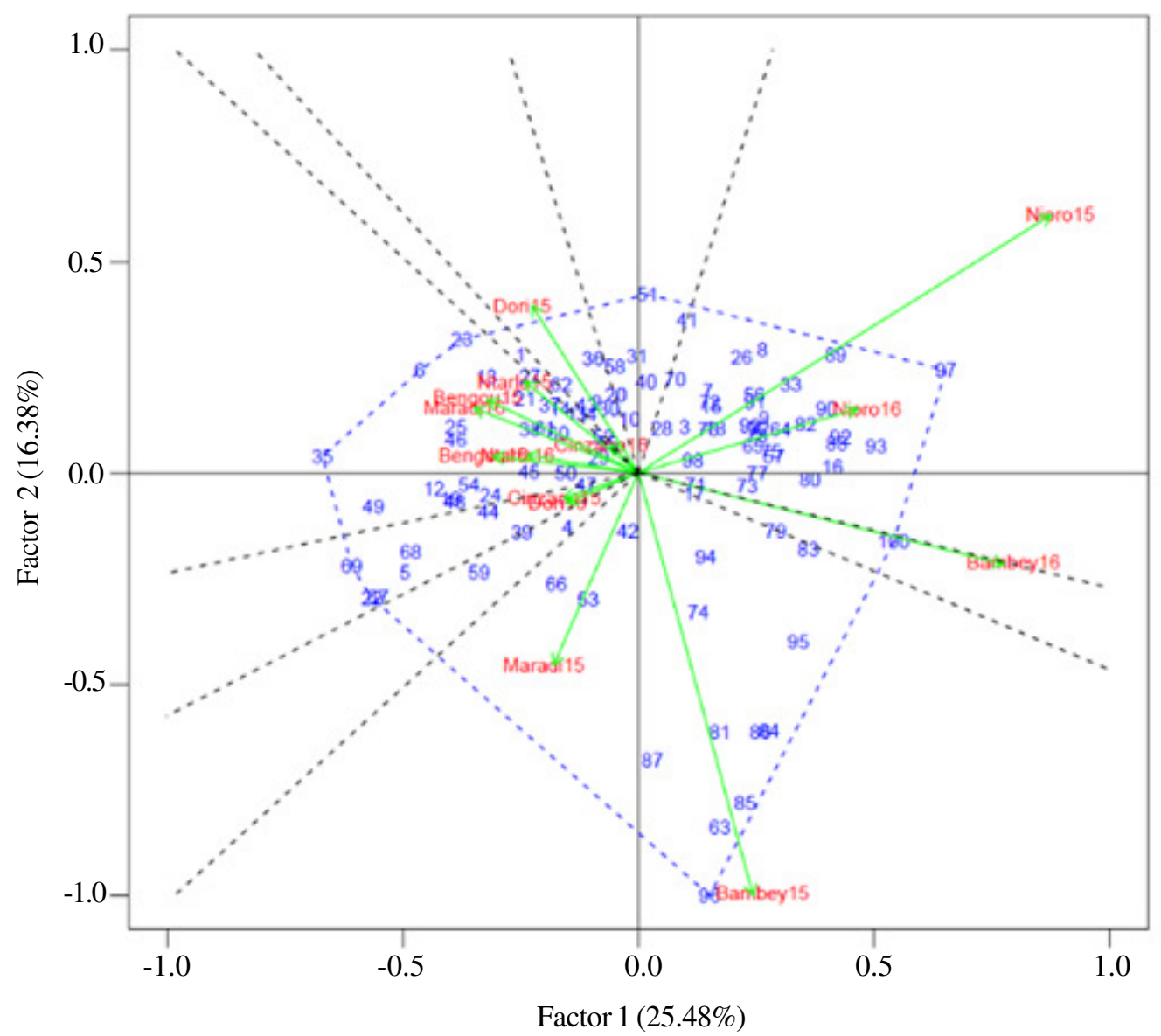

Figure 2. Principal components of the genotypes and environments. Factor 1 (PC1), 2 (PC2), and 3 (PC2) explained 25.48, 16.38, 13.24\% of the total variation, respectively. The environment names are location names and year combinations. 
AMMI PCA1 Score vs GYD from a RCB

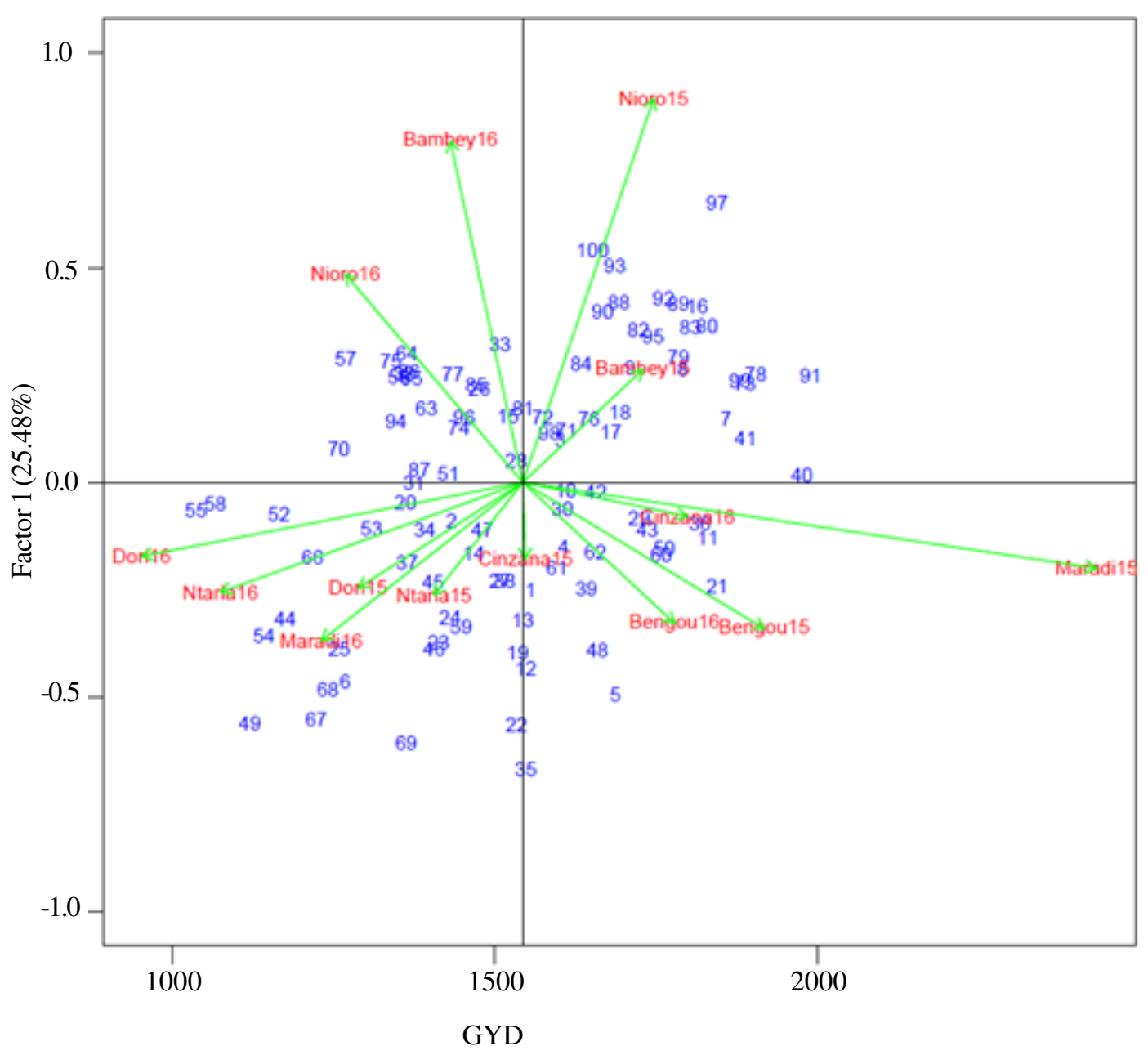

Figure 3. AMMI biplot illustrating the mean grain yield $\left(\mathrm{kg} \mathrm{ha}^{-1}\right)$ (main effect) vs. stability (IPC1 or factor 1) view of both genotypes (blue) and environments (red) for 100 genotypes evaluated at a total of 14 environments during 2015 and 2016 growing seasons. Environments names are as given in Figure 2.

were located at the vertices of the polygon. To the contrary, genotypes 49 (SMILML15), 52 (SMILML18), 55 (SMILNG1) and 58 (SMILNG4) showed the least overall mean grain yield performance. Genotypes distributed around the centre of the graph such as 3 (SMILBF3), 10 (SMILBF10), 14 (SMILBF14), 39 (SMILML5), 76 (SMILNG22) and 94 (SMILSG17) had more stable grain yield performance than the others.

In the present study, Sahelian (Dori, Burkina Faso; Maradi, Niger; N'tarla, Mali; and
Bambey, Senegal) and Sudanian (Cinzana, Mali and Bengou, Niger), as well as the locations described as Sudano-Sahelian (Nioro, Senegal) were included. Data analysis indicated that Maradi15, Nioro15, Bambey15, Cinzana16, Bengou 15, and Bengou 16 were categorised as high yielding environments.

Although different parameters are used by the two models, almost similar results were obtained. The two stability systems confirmed that genotypes 10 (SMILBF10), 14 (SMILBF14), 39 (SMILML5), 76 
(SMILNG22) and 94 (SMILSG17) are widely adaptable and should be considered for region wide variety release.

Yield stability usually refers to a genotype's ability to perform consistently across a wide range of spatial or temporal variations in agroclimatic conditions (Eberhart and Russell, 1966). Prevalence of genotype-byenvironment interaction (GEI) has a negative impact on the selection of crop cultivars based on overall mean performance per se. Therefore, analysis of stability of performance of a new genotype in a given set of environments is paramount to select a widely adaptable or a specifically adapted cultivar of a crop (Yan and Hunt, 2010).

Correlations among traits. The correlation coefficients among yield and contributing morphological and phenological traits showed that PNY, NPL, PLG and PHT were significantly and positively correlated with grain and fodder yields (Fig. 4). PNY ( $\mathrm{r}=$ $0.59)$ and NPL $(r=0.54)$ were the two most important GYD contributing factors. PHT and DFL showed significantly positive correlation with the fodder yield $(r=0.56$ and $r=0.35$, respectively). PHT also had significant positive

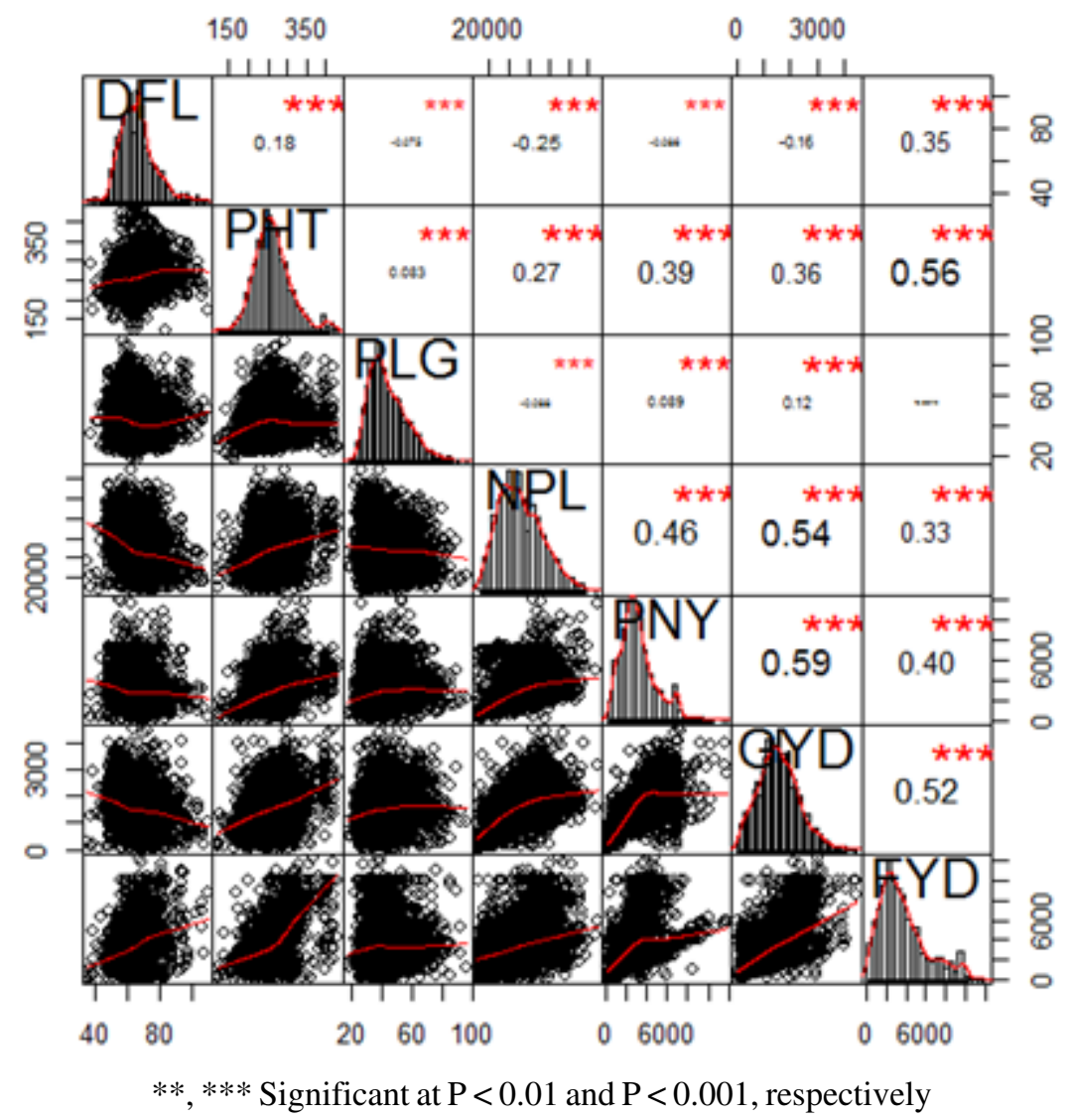

Figure 4. Scatter plots, frequency distributions, and relationships among the studied traits for 100 dual-purpose pearl millet accessions evaluated at a total of 14 environments during 2015 and 2016 in Burkina Faso, Mali, Niger, and Senegal. DFL = Days to 50\% flowering; PHT = Plant height (cm); PLG $=$ Panicle length $(\mathrm{cm}) ; \mathrm{NPL}=$ Number of panicles per hectare; $\mathrm{PNY}=$ Panicle yield $\left(\mathrm{kg} \mathrm{ha}^{-1}\right) ; \mathrm{GYD}=$ Grain yield $\left(\mathrm{kg} \mathrm{ha}^{-1}\right)$; and FYD $=$ Fodder yield $\left(\mathrm{kg} \mathrm{ha}^{-1}\right)$. 
correlation with GYD $(r=0.36)$. On the other hand, DFL had negative correlation $(r=-0.16)$ with grain yield implying that extremely late maturing genotypes are not preferred.

The correlation coefficients among the component traits indicated a general tendency that tall plants flowered later than the shorter accessions, but were not strongly correlated. On the other hand, tall plants had the advantage of increasing both grain and fodder yields. As the coefficient of correlation measures the strength and direction of a relationship between two traits (Sella and Barton, 2019), it is very important for effective indirect selection of complex traits like yield using simply measurable proxy traits such as PHT and NPL. Therefore, DFL, NPL, PNY, and PHT are important selection targets to improve both grain and fodder yields. In the evaluation for dual-purpose pearl millet, late flowering, tall plant height and panicle size and number are better be considered important characteristics for selection.

The two economically important traits, GYD and FYD were highly significantly and positively correlated (Fig. 4). This suggests that concomitant improvement for pearl millet fodder yield can be achieved through selection for tall genotypes from the landraces, without compromising grain yield. Based on overall mean grain and fodder yields, genotypes such as SMILML2, SMILML6, SMILBF11, SMILBF21, SMILSG20, and SMILSG22 presented outstanding performance. Therefore, these genotypes need to be further evaluated for release as a dual-purpose cultivar in the region.

In this study, PHT, PNY and PLG were most important traits for maximising grain and fodder yields because of their high significant positive correlation coefficients (Fig. 4). Previous studies also reported positive correlations of productive tillers, panicle length, panicle girth, days to maturity to grain yield in pearl millet (Govindaraj et al., 2013; Sattler et al., 2018). Similarly, genotypes with tall height, high panicle weight and panicle harvest index were indicated to likely increase grain yield in sorghum (Da Silva et al., 2017). Although DFL was positively correlated with FYD, its correlation with grain yield was negative, implying very late flowering genotypes are not preferred in breeding for dual-purpose millet varieties.

\section{CONCLUSION}

The two years evaluation of selected accessions from the breeding programmes in the West African region indicates the prevalence of ample germplasm resources for breeding dual-purpose pearl millet in the region. The result of the study showed a variation among the accessions tested, environments and GEI. Stability analysis using Eberhart and Russell as well as AMMI approaches identified several generally adaptable genotypes. Accordingly, SMILBF10 and SMILBF14 from Burkina Faso, SMILML5 from Mali, SMILNG22 from Niger, and SMILSG17 from Senegal had overall better performance. In general, population hybrids and composite varieties performed better than the open pollinated varieties across the environments. Regionally integrated breeding programmes with effective germplasm exchange and information sharing will have significant leveraging effect in developing desirable pearl millet cultivars in the region.

The significant positive correlation of grain and fodder yields with the major contributing traits such as PHT, PNL, and PNY can be leveraged in simultaneous indirect selection for high yielding dual-purpose cultivars.

\section{ACKNOWLEDGMENT}

We gratefully recognise all the technicians, and research assistants from the four countries (Burkina Faso, Mali, Niger and Senegal) for their contribution in the implementation of the field evaluation. Funding for this research was provided by the United States Agency for International Development under Cooperative Agreement No. AID-OAA-A-13-00047 with the Kansas State University Sorghum and 
Millet Innovation Lab (SMIL). The contents are solely the responsibility of the authors and do not necessarily reflect the views of USAID or others. Mention of trade names or commercial products in this paper is solely for the purpose of providing specific information and does not imply recommendation or endorsement by any part herein. This is contribution number 20-115-J from the Kansas Agricultural Experiment Station.

\section{REFERENCES}

Amodu, J.T., Adeyinka, I., Kallah, M. and Alawa, J.P. 2007. Evaluation of pearl millet accessions for yield and nutrient composition. Journal of Biological Sciences 7:379-383. doi: 10.3923/ jbs.2007.379.383.

Burgarella, C., Cubry, P., Kane, N.A., Varshney, R.K., Mariac, C., Liu, X., Shi, C., Thudi, M., Couderc, M., Xu, X., Chitikineni, A., Scarcelli, N., Barnaud, A., Rhoné, B., Dupuy, C., François, O., Berthouly-Salazar, C. and Vigouroux, Y. 2018. A western Sahara centre of domestication inferred from pearl millet genomes. Nature Ecology \& Evolution 2: 1377-1380. doi: 10.1038/s41559-0180643-y

Burton, G.W. 1974. Factors affecting pollen movement and natural crossing in pearl millet. Crop Science 14:802-805. doi: $10.2135 /$ cropsci1974.0011183X0014000 $60007 x$

Cornelius, P.L., Seyedsadr, M. and Crossa, J. 1992. Using the shifted multiplicative model to search for "separability" in crop cultivar trials. Theoretical and Applied Genetics 84: 161-172. doi: 10.1007/BF00223996

D'Andrea, A.C. and Casey, J. 2002. Pearl millet and Kintampo subsistence. African Archaeological Review 19:147-173.

Da Silva, K.J., Teodoro, P.E., De Menezes, C.B., Júlio, M.P.M., De Souza, V.F., Da Silva, M.J., Pimentel, L.D. and Borém, A. 2017. Contribution of morphoagronomic traits to grain yield and earliness in grain sorghum. Genetics and Molecular Research 16:1-10. doi: 10.4238/gmr16029649

Diack, O., Kane, N.A., Berthouly-Salazar, C., Gueye, M.C., Diop, B.M., Fofana, A., Sy, O., Tall, H., Zekraoui, L., Piquet, M., Couderc, M., Vigouroux, Y., Diouf, D. and Barnaud, A. 2017. New genetic insights into pearl millet diversity as revealed by characterization of early- and late-flowering landraces from Senegal. Frontiers in Plant Science 8:1-9. doi: 10.3389/fpls. 2017. 00818

Dussert, Y., Snirc, A. and Robert, T. 2015. Inference of domestication history and differentiation between early- and late flowering varieties in pearl millet. Molecular Ecology 24:1387-1402. doi: 10.1111/mec.13119

Eberhart, S.A. and Russell, W.A. 1966. Stability parameters for comparing varieties. Crop Science 6:36-40. doi: 10.2135/cropsci1966.0011183X 0006000 $10011 \mathrm{x}$

Fageria, N.K. 2007. Yield Physiology of Rice. Journal of Plant Nutrition 30:843-879. doi: 10.1080/15226510701374831

Fuller, D.Q. 2007. Contrasting Patterns in Crop Domestication and Domestication Rates: Recent Archaeobotanical Insights from the Old World. Annals of Botany 100: 903-924. doi: 10.1093/aob/mcm048

Gauch, H.G. 1988. Model selection and validation for yield trials with interaction. Biometrics 44: 705-715. doi: 10.2307/ 2531585

Gauch, H.G. and Zobel, R.W. 1988. Predictive and postdictive success of statistical analyses of yield trials. Theoretical and Applied Genetics 76:1-10. doi: 10.1007/ BF00288824

Govindaraj, M., Selvi, B. and Rajarathinam, S. 2013. Correlation studies for grain yield components and nutritional quality traits in pearl millet (Pennisetum glaucum (L.) R. Br.) germplasm. World Journal of Agricultural Sciences 5:686-689. 
Gowda, C.L.L., Serraj, R., Srinivasan, G., Chauhan, Y., Reddy, B.V.S., Rai, N., Nigam, S., Gaur, P., Reddy, L.J., Dwivedi, S., Upadhyaya, H., P H, Z., Rai, H.K., Maniselvan, P., Follkerstma, R. and Nalini, M. 2009. Opportunities for improving crop Water productivity through genetic enhancement of dryland crops. In: Rainfed Agriculture: Unlocking the Potential. pp. 133-163. doi: 10.1079/9781845933890. 0133

Haryanto, T.A.D., Shon, T.-K. and Yoshida, T. 1998. Effects of Selection for Yield Components on Grain Yield in Pearl Millet (Pennisetum typhoideum Rich.). Plant Production Science 1: 52-55. doi: 10.1626/ pps. 1.52

Hassan, M., Ahmad, A.-H., Zamir, S., Haq, I., Khalid, F., Rasool, T. and Hussain, A. 2014. Growth, yield and quality performance of pearl millet (Pennisetum americanum L.). American Journal of Plant Sciences 05: 2215-2223. doi: 10.4236/ajps.2014.515235

Haussmann, B.I.G., Boureima, S.S., Kassari, I.A., Moumouni, K.H. and Boubacar, A. 2007. Mechanisms of adaptation to climate variability in West African pearl millet landraces - A preliminary assessment. Journal of SAT Agricultural Research 3: 1-3.

Haussmann, B.I.G., Fred Rattunde, H., Weltzien-Rattunde, E., Traoré, P.S.C., vom Brocke, K. and Parzies, H.K. 2012. Breeding strategies for adaptation of pearl millet and sorghum to climate variability and change in West Africa. Journal of Agronomy and Crop Science 198: 327-339. doi: 10.1111/j.1439-037X.2012.00526.x

Jauhar, P.P. and Hanna, W.W. 1998. Cytogenetics and genetics of pearl millet. Advances in Agronomy 64: 1-26. doi: 10.1016/S0065-2113(08)60501-5

Maleko, D., Mwilawa, A., Msalya, G., Pasape, L. and Mtei, K. 2019. Forage growth, yield and nutritional characteristics of four varieties of napier grass (Pennisetum purpureum Schumach) in the west
Usambara highlands, Tanzania. Scientific African 6: e00214. doi: https://doi.org/ 10.1016/j.sciaf.2019.e00214

Manning, K., Pelling, R., Higham, T., Schwenniger, J.L. and Fuller, D.Q. 2011. 4500-Year old domesticated pearl millet (Pennisetum glaucum) from the Tilemsi Valley, Mali: New insights into an alternative cereal domestication pathway. Journal of Archaeological Science 38: 312-322. doi: 10.1016/j.jas.2010.09.007

Obeng, E., Cebert, E., Singh, B.P., Ward, R., Nyochembeng, L.M. and Mays, D.A. 2012. Growth and grain yield of pearl millet (Pennisetum glaucum) genotypes at different levels of nitrogen fertilization in the southeastern united states. The Journal of Agricultural Science 4:155.

Oosterom, E., Carberry, P.S. and O'Leary, G. 2001. Simulating growth, development, and yield of tillering pearl millet: I. Leaf area profiles on main shoots and tillers. Field Crops Research 72:51-66. doi: 10.1016/ S0378-4290(01)00164-2

Ouendeba, B., Ejeta, G., Hanna, W.W. and Kumar, A.K. 1995. Diversity among African pearl millet landrace populations. Crop Science 35:919-924. doi: 10.2135/ cropsci1995.0011183X003500030048x

Oumar, I., Mariac, C., Pham, J.-L.L. and Vigouroux, Y. 2008. Phylogeny and origin of pearl millet (Pennisetum glaucum [L.] $\mathrm{R}$. Br) as revealed by microsatellite loci. Theoretical and Applied Genetics 117: 489497. doi: 10.1007/s00122-008-0793-4

Pacheco, Á., Vargas, M., Alvarado, G., Rodríguez, F., Crossa, J. and Burgueño, J. 2018. GEA-R (Genotype x Environment Analysis with R for Windows) Version 4.1. doi: hdl/11529/10203

Poncet, V., Lamy, F., Enjalbert, J., Joly, H., Sarr, A. and Robert, T. 1998. Genetic analysis of the domestication syndrome in pearl millet (Pennisetum glaucum L., Poaceae): inheritance of the major characters. Heredity 81: 648-658. doi: 10.1046/j.1365-2540.1998.00445.x 
Purchase, J.L., Hatting, H. and van Deventer, C.S. 2000. Genotype $\times$ environment interaction of winter wheat (Triticum aestivum L.) in South Africa: II. Stability analysis of yield performance. South African Journal of Plant and Soil 17:101107. doi: 10.1080/02571862.2000.10634 878

Sanou, J., Bayala, J., Paulin, B. and Teklehaimanot, Z. 2012. Photosynthesis and biomass production by millet (Pennisetum glaucum) and taro (Colocasia esculenta) grown under baobab (Adansonia digitata) and néré (Parkia biglobosa) in an agroforestry parkland system of Burkina faso, West Africa. doi: 10.1017/ S0014479712000014

Sattler, F.T., Sanogo, M.D., Kassari, I.A., Angarawai, I.I., Gwadi, K.W., Dodo, H. and Haussmann, B.I.G. 2018. Characterization of West and Central African accessions from a pearl millet reference collection for agro-morphological traits and Striga resistance. Plant Genetic Resources: Characterisation and Utilisation 16: 260-272. doi: 10.1017/ S1479262117000272

Sella, G. and Barton, N.H. 2019. Thinking about the Evolution of Complex Traits in the Era of Genome-Wide Association Studies. Annual Review of Genomics and Human Genetics 20:461-493. doi: 10.1146/ annurev-genom-083115-022316

Upadhyaya, H.D., Reddy, K.N., Ahmed, M.I., Kumar, V., Gumma, M.K. and Ramachandran, S. 2017. Geographical distribution of traits and diversity in the world collection of pearl millet [Pennisetum glaucum (L.) R. Br., synonym: Cenchrus americanus (L.) Morrone] landraces conserved at the ICRISAT genebank. Genetic Resources and Crop Evolution 64: 1365-1381. doi: 10.1007/s10722-0160442-8

Varshney, R.K., Shi, C., Thudi, M., Mariac, C., Wallace, J., Qi, P., Zhang, H., Zhao, Y., Wang, X., Rathore, A., Srivastava, R.K.,
Chitikineni, A., Fan, G., Bajaj, P., Punnuri, S., Gupta, S.K., Wang, H., Jiang, Y., Couderc, M., Katta, M.A.V.S.K., Paudel, D.R., Mungra, K.D., Chen, W., HarrisShultz, K.R., Garg, V., Desai, N., Doddamani, D., Kane, N.A., Conner, J.A., Ghatak, A., Chaturvedi, P., Subramaniam, S., Yadav, O.P., Berthouly-Salazar, C., Hamidou, F., Wang, Jianping, Liang, X., Clotault, J., Upadhyaya, H.D., Cubry, P., Rhoné, B., Gueye, M.C., Sunkar, R., Dupuy, C., Sparvoli, F., Cheng, S., Mahala, R.S., Singh, B., Yadav, R.S., Lyons, E., Datta, S.K., Tom Hash, C., Devos, K.M., Buckler, E., Bennetzen, J.L., Paterson, A.H., Ozias-Akins, P., Grando, S., Wang, Jun, Mohapatra, T., Weckwerth, W., Reif, J.C., Liu, X., Vigouroux, Y. and Xu, X. 2017. Pearl millet genome sequence provides a resource to improve agronomic traits in arid environments. Nature Biotechnology 35:969-976. doi: 10.1038/ nbt.3943

Wilson, J.P., Burton, G.W., Zongo, J.D. and Dicko, I.O. 1990. Diversity among pearl millet landraces collected in central Burkina Faso. Crop Science 30:40-43. doi: 10.2135/ cropsci1990.0011183X00300 0010009x

Winkel, T., Renno, J.F. and Payne, W.A. 1997. Effect of the timing of water deficit on growth, phenology and yield of pearl millet (Pennisetum glaucum (L.) R Br) grown in Sahelian conditions. Journal of Experimental Botany 48:1001-1009. doi: 10.1093/jxb/48.5.1001

Yadav, O.P. and Bidinger, F. 2008. Dualpurpose landraces of pearl millet (Pennisetum glaucum) as sources of high stover and grain yield for arid zone environments. Plant Genetic Resources: Characterization and Utilization 6:73-78. doi: 10.1017/S1479262108993084

Yan, W. and Hunt, L. 2010. Genotype by environment interaction and crop yield. Plant Breeding Reviews 16:135-178. doi: 10.1002/9780470650110.ch4 